\title{
Authors reply: Diagnosis of a single imported dengue case who had travelled to Japan - how serious is it for travellers?
}

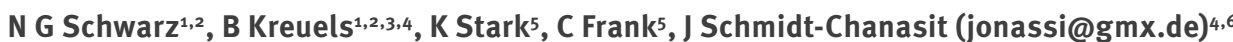

1. Bernhard Nocht Institute for Tropical Medicine, Infectious Disease Epidemiology, Hamburg, Germany

2. These authors contributed equally to this work

3. Division of Tropical Medicine, 1. Department of Internal Medicine, University Medical Centre Hamburg Eppendorf, Hamburg, Germany

4. German Centre for Infection Research (DZIF), partner site Hamburg-Luebeck-Borstel, Hamburg, Germany

5. Robert Koch Institute, Department for Infectious Disease Epidemiology, Division of Gastrointestinal Infections, Zoonoses and Tropical Infections, Berlin, Germany

6. Bernhard Nocht Institute for Tropical Medicine, WHO Collaborating Centre for Arbovirus and Haemorrhagic Fever Reference and Research, Hamburg, Germany

Citation style for this article:

Schwarz NG, Kreuels B, Stark K, Frank C, Schmidt-Chanasit J. Authors reply: Diagnosis of a single imported dengue case who had travelled to Japan - how serious is it for travellers?. Euro Surveill. 2014;19(8):pii=20716. Available online: http://www.eurosurveillance.org/ViewArticle.aspx?Articleld=20716

Article submitted on 5 February 2014 / published on 27 February 2014

To the editor: We would like to thank Ueno and Nishiura for their comments [1] on our paper entitled 'Autochthonous dengue virus infection in Japan imported into Germany, September 2013' [2]. We would like to clarify that we fully agree with our Japanese colleagues regarding the low risk of acquiring dengue virus (DENV) infections in Japan. It was never our aim to create any form of hysteria about the autochthonous DENV transmission in Japan and we do not recommend the issuing of a travel warning based on one reported case. As stated in the manuscript, we rather consider our reported case as a reminder to clinicians to consider dengue fever as a differential diagnosis, both in Japan and in travel clinics worldwide. There are documented cases of misdiagnosed DENV infections in travellers that resulted in a fatal outcome [3].

Nonetheless, we think that the calculations presented by Ueno and Nishiura in their letter to the editor should be interpreted with caution: while the epidemiological concepts behind the formulae seem sound, and thus may lead to arithmetically precise results, which indeed suggest a low risk for DENV becoming endemic or epidemic in Japan, our current assumptions are based on only one case. Thus, the variability of databased estimates is high. The author's state, 'However, dengue was not at the forefront of Japanese physicians' attention before the case report'. This implies that some dengue cases may have remained undetected. The majority of DENV infections present with few and often non-specific symptoms [4] and it is particularly likely that cases remain undetected if DENV transmission is restricted to only a short period in summer, as has been reported from Croatia and France [5-7].
The detection of one case, with the possibility of other undetected cases, demonstrates that there is a risk for dengue outbreaks in Japan, although we agree with the authors' conclusion that the risk of dengue becoming endemic is small. Dengue outbreaks in Japan were reported between 1942 and 1945 [8]. Certainly transmission may have taken place at Narita International Airport, where the presence of Aedes aegypti has recently been demonstrated [9]. However, the information of 'numerous mosquito bites' received while grape picking in Fuefuki, Japan, during the hottest month of the year, suggests the possibility that our patient was infected in the Japanese countryside, with mosquito's infection originally 'seeded' by an imported infection. Both potential scenarios could be further examined by human serosurveys in the respective prefectures and at the airports and by entomological investigations assessing the abundance of mosquito vectors and their DENV infection rates. Such investigations were immediately performed in Croatia in 2010, after we reported the first autochthonous dengue fever case for Croatia and Europe $[5,6]$. These investigations revealed important findings, such as the serotype and genotype of the circulating DENV in Croatia [10]. In addition, hospitalbased surveillance for dengue fever cases in Japan may strengthen risk assessments and forecasting models. We would highly welcome such investigations by our Japanese colleagues.

Conflict of interest

None declared. 
JSC and CF wrote a draft response, NGS, BK and KS verified the analysis and provided comments, and all authors approved the final version

\section{References}

1. Ueno R, Nishiura H. Letter to the editor: Diagnosis of single imported dengue case who had travelled to Japan - how serious is it for travellers? . Euro Surveill. 2014;19(8): $\mathrm{pii}=20715$.

2. Schmidt-Chanasit J, Emmerich P, Tappe D, Günther S, Schmidt $\mathrm{S}$, Wolff $\mathrm{D}$, et al. Autochthonous dengue virus infection in Japan imported into Germany, September 2013. Euro Surveill. 2014;19(3):pii=20681. Available from: http://www. eurosurveillance.org/ViewArticle.aspx?Articleld=20681

3. Schmidt-Chanasit J, Tenner-Racz K, Poppert D, Emmerich $P$, Frank C, Dinges C, et al. Fatal dengue hemorrhagic fever imported into Germany. Infection. 2012;40(4):441-3. http:// dx.doi.org/10.1007/s15010-011-0208-3

4. Gordon A, Kuan G, Mercado IC, Gresh L, Avilés W, Balmaseda A, et al. The Nicaraguan pediatric dengue cohort study: incidence of inapparent and symptomatic dengue virus infections, 2004-2010. PLoS Negl Trop Dis. 2013;7(9):e2462. http://dx.doi.org/10.1371/journal.pntd.0002462

5. Schmidt-Chanasit J, Haditsch M, Schoneberg I, Gunther S, Stark K, Frank C. Dengue virus infection in a traveller returning from Croatia to Germany. Euro Surveill. 2010;15(40):pii=19677.

6. Gjenero-Margan I, Aleraj B, Krajcar D, Lesnikar V, Klobučar A, Pem-Novosel I, et al. Autochthonous dengue fever in Croatia, August-September 2010. Euro Surveill. 2011;16(9): pii=19805.

7. La Ruche $G$, Souarès $Y$, Armengaud A, Peloux-Petiot F, Delaunay $P$, Desprès $P$, et al. First two autochthonous dengue virus infections in metropolitan France, September 2010. Euro Surveill. 2010;15(39):19676.

8. Takasaki T. Imported dengue fever/dengue hemorrhagic fever cases in Japan. Trop Med Health. 2011;39(4 Suppl):13-5. http:// dx.doi.org/10.2149/tmh.2011-So7

9. Sukehiro N, Kida N, Umezawa M, Murakami T, Arai N, Jinnai T, et al. First report on invasion of yellow fever mosquito, Aedes aegypti, at Narita International Airport, Japan in August 2012. Jpn J Infect Dis. 2013;66(3):189-94. http://dx.doi.org/10.7883/ yoken.66.189

10. Kurolt IC, Betica-Radić L, Daković-Rode O, Franco L, Zelená $\mathrm{H}$, Tenorio A et al. Molecular characterization of dengue virus 1 from autochthonous dengue fever cases in Croatia. Clin Microbiol Infect. 2013;19(3):E163-5. http://dx.doi. org/10.1111/1469-0691.12104 